\title{
Migración colombiana en la Ciudad de México, fronteras étnicas y estereotipos: una exploración autoetnográfica*
}

\author{
NATHALIA GUEVARA JARAMILLO**
}

\begin{abstract}
Colombian Migration to Mexico City, Ethnic Frontiers And Stereotypes: A Self-Ethnographic Exploration. This paper gathers the results of an exploratory exercise carried out by the author, a Colombian woman living in Mexico, regarding some stereotypes assigned to migrants from her country. Such study was carried out by means of self-ethnography, which makes possible to validate self-experience as ethnographic information. It states that stereotypy allows to reaffirm cultural frontiers based on the nationality, and the frontier is understood as a symbolic and cultural limit that makes possible to reassert the differences and belonging to a national group.
\end{abstract}

Key words: Colombian immigrants in Mexico, stereotypy, cultural frontiers, national identities

\begin{abstract}
Resumen
El artículo reúne los resultados de un ejercicio exploratorio realizado por la autora, una mujer de nacionalidad colombiana residente en México, en torno a algunos estereotipos asignados a los migrantes de su país. Tal exploración se llevó a cabo mediante la autoetnografía, la cual hace posible validar como información etnográfica la experiencia propia. Se plantea que la estereotipia permite reafirmar fronteras culturales basadas en la nacionalidad, y se entiende la frontera como un límite simbólico y cultural que hace posible la reafirmación de las diferencias y las pertenencias a un colectivo nacional.
\end{abstract}

Palabras clave: migrantes colombianos en México, estereotipia, fronteras culturales, identidades nacionales

$\mathrm{E}$ 131 de julio de 2015 fueron asesinadas cinco personas en un departamento de la calle Luz Saviñón, en la colonia Narvarte, en la Ciudad de México. La primera de las víctimas identificadas fue el fotógrafo Rubén Espinosa. Con el paso de las horas y los días, fueron apareciendo a cuentagotas algunas noticias sobre la identidad de las cuatro mujeres asesinadas: Nadia Vera, proveniente de Veracruz, amenazada allí; Alejandra Negrete, una empleada doméstica que venía del Estado de México; Yesenia Quiroz, una joven maquillista de Mexicali que estudiaba en la Ciudad de México; y Mile Virginia Martín, una colombiana que había migrado a México en 2010 y, al parecer, compartía el departamento con Nadia, Yesenia y un la tercera mujer que no se encontraba en el momento del crimen. En la prensa, el relato que circuló sobre Mile Virginia difundió la imagen de una mujer dedicada a la ilegalidad, asociada con criminales y con una sexualidad "fácil" y cuestionable. La historia pareció repetirse un año después con la muerte de una joven modelo colombiana llamada Stephanie Magón Flores, ocurrida en la colonia Nápoles, también en la Ciudad de México. Al principio, las autoridades

\footnotetext{
* Artículo recibido el 29/05/17 y aceptado el 07/11/17.

** Universidad Nacional Autónoma de México (unAm), Programa de Becas Posdoctorales en la unAm, becaria del Instituto de Investigaciones Sociales, asesorada por la doctora Natividad Gutiérrez Chong. Universidad Nacional Autónoma de México, Instituto de Investigaciones Sociales. Circuito Exterior, Ciudad Universitaria, Coyoacán, 04510, Ciudad de México <nataguevara@yahoo.com>.
} 
reconocieron que Stephanie tenía lesiones múltiples que sugerían que había sido golpeada, pero después cambiaron su versión y establecieron que se trataba de un suicidio, a pesar de haberla hallado tirada en la calle, desnuda y con golpes en varias partes del cuerpo, luego de que siguiera una trayectoria parabólica al caer de la azotea del edificio donde vivía (Animal Político, 2016).

Inicio mi artículo contando estos hechos porque, si hablamos de migración colombiana y estereotipos, es inevitable referirse a los homicidios de mujeres colombianas en México y a la forma en que éstos han sido abordados en la prensa, así como a la recurrente falta de esclarecimiento de tales crímenes por parte de las autoridades. Es como si el estereotipo con el que a menudo se asocia a las y los colombianos, el del narcotráfico y la prostitución, fuera razón suficiente para asumir que las víctimas se buscaron lo que les pasó. Las causas del fallecimiento tanto de Mile como de Stephanie siguen siendo inciertas; en la prensa, las víctimas han sido relacionadas con la fiesta, las drogas y la ilegalidad, lo cual ha servido para justificar su muerte y ha hecho pasar a un segundo plano la búsqueda de la verdad sobre estos hechos.

Los casos de Mile y Stephanie son apenas algunos ejemplos de la violencia de género cotidiana hacia las mujeres migrantes en México, lo que, a mi parecer, plantea la necesidad de hablar de estos asuntos y de nombrarlos con palabras concretas, como estereotipia, discriminación, xenofobia y violencia de género. Desde que me formé en antropología, la etnografía ha sido para mí una experiencia transformadora, y se me ocurrió que, entonces, podría también ser terapéutica. Por ello, me di a la tarea de documentar estas cuestiones por medio de un ejercicio autoetnográfico exploratorio, en el cual utilicé técnicas etnográficas como la conversación informal, la observación participante (que, en mi caso, fue más bien una "participación observante") en situaciones cotidianas en las que interactué con hombres y mujeres principalmente de nacionalidad colombiana y mexicana, además de la elaboración de notas de campo. Al comenzar este ejercicio, me preguntaba sobre qué estereotipos podría identificar, si éstos facilitaban el establecimiento de fronteras sociales en la vida cotidiana, su relación con prácticas de poder y de violencia, y su implicación en la creación de identidades nacionales y transnacionales. Inicié esta pesquisa con la idea de rastrear dos formas de estereotipos: los que un grupo le asignan a los otros (heteroestereotipo), y aquellos que esos otros se asignan a sí mismos (autoestereotipo) (Byram y Zarate, 1995). En el presente artículo, me centraré en la primera de esas dimensiones y esbozaré algunas ideas para el estudio de la segunda, la cual requiere un nivel aún más profundo de análisis y de registro de las experiencias de vida, puesto que conlleva el cuestionamiento de formas propias de concebir el mundo, así como una nueva etapa de trabajo de campo. Para mí, éste ha sido un ejercicio permanente que, al involucrar de manera tan directa la subjetividad, se encuentra inconcluso. En las páginas que siguen, haré algunas reflexiones en torno a las posibilidades y limitaciones de la autoetnografía; luego, examinaré diversos registros autoetnográficos a la luz del concepto de estereotipo e identificaré algunos de ellos para después vincularlos con la construcción de las culturas nacionales y las fronteras étnicas. En la conclusión, intentaré establecer un nexo entre las formas estereotipadas de representación asignadas a las y los migrantes de nacionalidad colombiana, y ciertos discursos y prácticas de xenofobia que ameritarían mayor estudio y análisis.

\section{La autoetnografía como herramienta para dar sentido a la experiencia de la migración}

Al hablar de autoetnografía, hago referencia a un método de investigación etnográfico que busca valorar las experiencias de vida propia y ponerlas en un contexto cultural más amplio o, como dice la antropóloga Heewon Chang (2008: 46; 2013: 108), generar una comprensión cultural de las experiencias biográficas, propósito para el cual el material autobiográfico se convierte en información etnográfica primaria. Desde esta perspectiva, se explora el vínculo entre la o el investigador y su entorno y se usan métodos de la etnografía (el diario y / o las notas de campo, la observación y la participación, la revisión de otras fuentes documentales, las conversaciones informales y las entrevistas). En otras palabras, la escritura biográfica es autoetnográfica si parte de una metodología etnográfica, orienta su interpretación hacia la dimensión cultural de la propia experiencia y trabaja con base en lo autobiográfico. Para Chang (2013: 108-109), el uso de información personal permite a la autoetnografía expandir la comprensión de las experiencias humanas en contextos sociales y culturales desde el punto de vista de quien investiga. Las historias personales, dice la autora, pueden convertirse de este modo en vehículos para la crítica social y posibilitar que los lectores ganen comprensión de las realidades sociales del etnógrafo y de las fuerzas sociales en las que se enmarca su experiencia.

Aunque el término autoetnografía se empleó por primera vez desde finales de la década de 1970 (Chang, 
2008: 47), ${ }^{1}$ este género es parte de una tendencia que ya enunciaba James Clifford (1995) cuando advertía acerca de la "quiebra de la autoridad etnográfica", la cual se había consolidado durante la primera mitad del siglo xx, cuando los antropólogos sociales establecieron el método etnográfico como práctica que validaba sus conocimientos sobre otras sociedades humanas.

Durante la primera mitad del siglo xx, la experiencia del etnógrafo en terrenos extraños adquirió validez como palabra experta sobre otras culturas. Ribeiro (1989) se refiere al "extrañamiento" como un fundamento de la mirada de los antropólogos desde que, con la obra de Malinowski, el trabajo de campo se convirtió en un elemento cardinal de nuestro método y de la legitimidad de nuestras interpretaciones. Así, en el terreno, los etnógrafos se enfrentan a una situación de aproximación y de distanciamiento al participar como no nativos en las prácticas sociales que estudian. Sin embargo, con la quiebra o el desplazamiento de esta autoridad etnográfica, surgen alternativas de escritura que no parten de una distinción tajante entre sujetos y autores. La autoetnografía es un ejemplo de estas nuevas formas textuales y de conocimiento etnográfico. Con el reconocimiento del carácter autobiográfico de la etnografía, las narrativas personales han ganado el estatuto de "escritura etnográfica legítima", aunque no exista un consenso sobre el peso de lo personal en una etnografía y las experiencias biográficas tiendan aún a ponerse en apartados separados del análisis etnográfico (Coffey, 1999: 17-18).

Aquí es donde la experiencia de vida de los migrantes y la autoetnografía se cruzan. La migración constituye una fuente de situaciones de extrañamiento porque, a pesar de que uno sume años viviendo en su país de acogida, ser extranjero es una condición permanente y que parece imposible de abandonar. Si el etnógrafo trata de convertir lo extraño o lo exótico en familiar, al estudiar su propia sociedad, dice Ribeiro (1989), hace una operación inversa, es decir, convierte lo familiar en exótico. Ése fue uno de los propósitos de mi ejercicio: distanciarme de mis propias experiencias para tratar de releerlas como situaciones inmersas en un contexto cultural particular.

A pesar de que la autoetnografía puede ser una estrategia metodológica y narrativa para dar valor a las experiencias de vida de quien investiga, su práctica presenta un desafío porque implica distanciamiento y cuestionamiento de las propias vivencias y formas de ver el mundo, las cuales pueden parecer casi naturales $\mathrm{y}$, por tanto, incuestionables. Así pues, la autoetnografía, como la etnografía, supone un extrañamiento: esta vez con una misma y con sus propias experiencias, así como un trabajo dedicado para lidiar con la fragilidad y selectividad de la memoria, lo cual hace necesario sistematizar de manera juiciosa la información y realizar notas de campo de modo oportuno. Éste ha sido uno de los retos de mi ejercicio autoetnográfico. No siempre es más fácil hablar o escribir sobre la propia experiencia, como tampoco lo es someterse a cuestionarla, desarmarla, distanciarse de ella y exponerla.

Por supuesto, utilizar experiencias biográficas y autobiográficas individuales como materia prima etnográfica conlleva limitaciones. Aunque la exploración de experiencias individuales desde una perspectiva etnográfica plantea un acercamiento privilegiado a un punto de vista subjetivo y personal, uno de los cuestionamientos hacia este enfoque es que puede llegar a concederle una voz privilegiada al narrador y aislarlo de su contexto social y cultural en lo que Atkinson (1997: 335) denomina una "celebración romántica del sujeto individual”. A su vez, Coffey (1999: 37) advierte que, aunque no podemos negar nuestra implicación en lo que estudiamos, hacernos a nosotras o nosotros mismos el centro del análisis podría restarle riqueza a nuestro trabajo etnográfico, dado que estamos llamados a dar cuenta de los mundos sociales de los otros. Según la autora, nos concedemos demasiada importancia al creer que podemos convertirnos en uno más dentro del escenario que investigamos.

Aquí, la crítica de fondo es la dificultad de ubicar las narrativas autoetnográficas dentro de mundos culturales más amplios o, visto de otra manera, la representatividad de las experiencias autobiográficas. Si bien un ejercicio autoetnográfico no reemplaza la riqueza y complejidad de una etnografía enfocada hacia lo colectivo, convertir la experiencia personal en información etnográfica permite una mirada personal y única a vivencias que no están desconectadas de su contexto social. Esta dimensión personal nunca se encuentra desligada del mundo social o, en otras palabras, individuo y cultura están entrelazados. Por ello, las narrativas autoetnográficas no sólo abren una ventana para la comprensión propia, sino también para dar sentido a las prácticas de otros seres humanos. En este aspecto, una narrativa personal no será autoetnográfica si no incorpora análisis e interpretación cultural profundos (Chang, 2008: 13, 44).

\footnotetext{
1 Hay que aclarar que, en aquel entonces, la autoetnografía fue la palabra utilizada para referirse al estudio de la cultura del propio etnógrafo, es decir, a una circunstancia en la cual el etnógrafo es también un "nativo" (Walford, 2004: 410).
} 
La validación de experiencias autobiográficas como materia prima etnográfica no implica negar las limitaciones de este enfoque ni tampoco desconocer la necesidad de enriquecerlo con los puntos de vista de otros actores. En este caso, la perspectiva autoetnográfica permite avanzar en la aproximación a un problema antropológico concreto, vigente y poco abordado en la literatura sobre la migración colombiana hacia México; de este modo, la narrativa personal adquiere relevancia en la medida en que contribuye a la comprensión de una realidad social escasamente documentada. Al respecto, vale la pena destacar que, aunque la diáspora colombiana en México es una de las más numerosas, su presencia en el país continúa siendo muy poco estudiada, y la mayor parte de los datos con los que contamos provienen de aproximaciones demográficas. ${ }^{2}$ En este ejercicio, la experiencia autobiográfica en sí misma resultaría irrelevante si no pudiera enmarcarse en metodologías y teorías de las ciencias sociales ni convertirse en material de análisis antropológico y social.

Otra limitación de este enfoque tiene que ver con la dificultad, señalada antes, de alcanzar un estado de extrañamiento con respecto a las experiencias biográficas. Sin embargo, la idea de que el extrañamiento es una condición obligatoria para la comprensión antropológica de universos sociales y culturales podría no comprender todas las experiencias de campo, ni tampoco las negociaciones que ocurren en él (Coffey, 1999: 37). En otras palabras, una mayor distancia o extrañeza con respecto al mundo social que nos interesa conocer no nos hace, de manera automática, mejores etnógrafos.

Walford (2004: 411-412) advierte sobre algunos problemas en torno a la verdad de los datos autoetnográficos, así como una mayor cercanía a la terapia que a la investigación social. En relación con el primer aspecto, es importante recordar que cualquier narrativa sobre la vida social está sujeta a diversas interpretaciones. Walford, empero, advierte sobre la dificultad de establecer lo que es factual en algunos relatos autoetnográficos. En esta crítica hay aspectos éticos que tienen que ver con la sistematicidad de quien investiga para registrar los hechos en notas, así como con su autoridad y responsabilidad a la hora de presentar información veraz. Aunque su preocupación es insoslayable, debe reconocerse que, como ocurre en otros registros de campo, la información biográfica también está sujeta a la memoria de quien la escribe. Por tal razón, este ejercicio requiere una disposición constante para dejar asentadas las experiencias biográficas, además de una postura ética que considere dichas experiencias como información que, más que satisfacer la autoindulgencia, permita comprender un problema social determinado. En cuanto a la segunda objeción, el tipo de terapia y su efectividad son aspectos subjetivos. Si se trata de desahogarse, uno puede escribir cuentos, poemas o novelas; pero si uno se decide por la autoetnografía, el desahogo no será una catarsis amorfa, sino un intento por racionalizar experiencias subjetivas utilizando las herramientas y las categorías de la investigación social.

\section{La vivencia de los estereotipos}

El hecho que desató este ejercicio fue la muerte violenta, en 2015, de cinco personas en la colonia Narvarte, como ya relaté. Una de las víctimas, Mile Virginia Martín, era una ciudadana colombiana que había llegado al país el mismo año que yo y que vivía a unas cuantas cuadras de mi departamento. La versión de los medios me parecía vagamente familiar porque se asemejaba, guardadas las proporciones, a las ideas estereotipadas que había escuchado en distintas situaciones sociales definidas por mi nacionalidad (o narradas por otros migrantes colombianos residentes en la Ciudad de México): Mile, de quien se presumía que se dedicaba a la prostitución, habría estado también involucrada en tráfico de drogas y vinculada con bandas criminales

2 Por ejemplo, Neira Orjuela (2010). Este autor (2010: 415) destaca la casi total ausencia de estudios sobre el tema. Es importante señalar que a partir de mediados de la década de 1990 se acentuaron los flujos migratorios de ciudadanos colombianos hacia el exterior, lo cual podría atribuirse a la crisis económica y al recrudecimiento del conflicto armado. Establecer las cifras de colombianos residentes en el exterior es complejo, debido a que en las fuentes oficiales existe un subregistro. No obstante, de acuerdo con el censo realizado en Colombia en 2005, México es el séptimo país a donde más emigran los colombianos, con 1.1\% del total de los migrantes. Entre 1990 y 2005, Colombia mantuvo el primer lugar entre los países sudamericanos en el registro de emigrantes (véase Cárdenas y Mejía, 2006). Según cifras del Instituto Nacional de Migración de México correspondientes al año 2009, habría 14610 colombianos residiendo de manera permanente en México, lo cual nos convierte en la cuarta colonia más grande en este país, después de estadounidenses, españoles y argentinos (véase Rodríguez Chávez y Cobo, 2012). Entre enero y agosto de 2016, así como durante todo el 2013, los colombianos fueron la tercera nacionalidad que más solicitó y renovó tarjetas de residente permanente. Otras cifras con base en la Comisión Económica para América Latina y el Caribe, el Observatorio Demográfico y el Censo de Población y Vivienda de 2010, arrojan la existencia de 12832 residentes colombianos en México en 2010 , lo que sitúa a esta colonia en el quinto lugar entre las más grandes en este país (véase Caicedo y Morales Mena, 2015). 
responsables del delito. ${ }^{3} \mathrm{Si}$ bien estas acusaciones se difundieron con rapidez, los medios que las presentaron no aportaron evidencia que las comprobara. Algunos meses después del crimen, el Consejo para Prevenir y Eliminar la Discriminación de la Ciudad de México (Copred) emitió una opinión consultiva respecto de la información que circuló en los medios de comunicación sobre las cinco víctimas, y concluyó que "se advertían conductas discriminatorias en el manejo dado a la información, al difundirse mediante lenguaje con estereotipos, prejuicios, estigmas e incluso mediante la criminalización de las víctimas, lo que se traduce en injerencias en su reputación" (Copred, 2015: 27). Este hito me hizo considerar la importancia de documentar algunos estereotipos que se difundieron en la prensa de la época y que coincidían con varias experiencias personales como extranjera residente en esta urbe.

En 2015 estuve participando en un proyecto de salud pública en la Ciudad de México. En una salida al campo, debía entrevistar a una mujer con enfermedad renal crónica que trabajaba en un mercado. Me interesaba conocer la experiencia de vida de mi entrevistada en cuanto a su padecimiento, su historia con la enfermedad, los pormenores de su tratamiento y los obstáculos que había encontrado en el proceso, entre otras cosas. Sin embargo, al encontrarme con ella, la conversación se centró en mi nacionalidad. "Eres colombiana, ¿verdad?”, “¿y cuánto tiempo llevas aquí?” Y continuó: "Aquí no quieren a los colombianos. Habla bajito". " Contaba que una banda de extorsionadores colombianos había azotado a los comerciantes de la zona, y que un grupo de personas de esa nacionalidad se reunían en un local ubicado a media cuadra de su lugar de trabajo a recibir cargamentos extraños. Días atrás, cuando le hablé por teléfono para concertar el encuentro, saber que yo era colombiana le causó miedo. Su familia se oponía a que participara en el proyecto de investigación del cual yo formaba parte. Lo que yo interpreté como resistencia a platicar conmigo sobre su salud, terminó siendo temor y prejuicio hacia mi nacionalidad. La barrera fue posible de franquear debido a que una de sus amigas había accedido a hablar conmigo en el marco del mismo proyecto de investigación. Sin saber qué hacer ante esta bienvenida, me reí y le dije, "no te preocupes, te prometo que no te voy a extorsionar". Su papá, quien no había estado presente en la conversación previa, se perdió mis intentos por revertir el estereotipo y, por eso, cuando me lo presentaron, respondió con una mirada de reojo y un comentario entre dientes: "Colombiana, ¿qué trae?”

En 2013, mi pareja y yo encontramos por casualidad en la calle a un conocido quien, al enterarse de que yo era colombiana, señaló: "En Colombia hay buen café, café del otro” (mientras hacía con sus dedos el ademán de fumar). Me tardé un lapso incierto, entre minutos y años, en procesar su comentario hecho en forma de chiste. Esta asociación ha sido común desde que vivo fuera de mi país. Otro conocido, una persona con formación académica en una importante universidad, afirmaba con certeza que en Colombia se cultiva y consume coca con más frecuencia, a pesar de que nunca ha visitado el país y de que yo le respondí que, en la vida cotidiana, había visto más drogas y consumo desde que vivo en México. Mi interlocutor asumía que, en Colombia, la droga se comercializa y consume de manera generalizada, como artículo de primera necesidad. Al cuestionar esta visión, él argumentaba que quienes provenimos de los países andinos estamos acostumbrados al uso de la hoja de coca en nuestro día a día (práctica que aún realizan las comunidades indígenas y de la que yo, como originaria de un contexto urbano, apenas tuve noticia mientras estudiaba antropología). Vale la pena recordar que el uso ritual o cotidiano que todavía hoy hacen ciertos pueblos indígenas de la hoja de coca nada tiene que ver con la producción, comercio y consumo de cocaína en Colombia y en otros países sudamericanos, pues está acotado a contextos culturales que le confieren sentidos y funciones distintas a la planta.

Días antes de esta discusión, había estado en una fiesta en el departamento de una compañera de clase y vecina de nacionalidad mexicana. Después de unas cuantas cervezas decidí irme. Ella y uno de sus amigos me acompañaron a casa. Mientras caminábamos, él contaba que quería ir a Colombia porque las mujeres le parecían muy guapas y le gustaría "conseguirse una”. De hecho, por esta razón, seguía a varias colombianas

$3 \mathrm{Al}$ respecto, véanse notas de prensa tales como "Viajaba por todo el mundo prostituta colombiana asesinada en la Narvarte" (Primer Sistema de Noticias), "Colombiana usaba como casa de citas departamento de la Narvarte" (Vanguardia), "Colombiana asesinada en Narvarte pidió visa con papeles falsos" (Multimedios), "Caso Narvarte: "Mile traficaba drogas y era prostituta en Europa”" (Notinfomex) o "Cargamento de droga, móvil del multihomicidio de la Narvarte" (Letra Roja), entre otras. Todas estas noticias, que circularon durante las semanas posteriores al hecho, pueden ser consultadas en internet.

4 Sobre el carácter de verdad de los relatos autoetnográficos y el uso de comillas para citar el lenguaje hablado, véase Walford (2004). El autor cuestiona el uso de las comillas en las narrativas autoetnográficas, en tanto no encierran declaraciones registradas en grabaciones de audio sino en reconstrucciones posteriores a los hechos. En este caso, las citas entre comillas provienen de registros de campo. 
en redes sociales. Ante su insistencia y sus efusivas expresiones de gusto por las colombianas, yo respondí que en México también había mujeres lindas y que la belleza es algo relativo, pero él persistía. Irritada por la charla, le respondí: “¿Y qué tal si yo te dijera que yo vengo a México porque espero encontrar güeyes en sarape recostados en un nopal? ¿Qué tal si yo te dijera que, para mí, México se reduce a eso?” Mi interlocutor se quedó en silencio dos segundos y comentó, “ah, claro, ya entiendo tu punto", sin embargo, un instante después retomó la plática previa. Aunque mi conocida apoyaba mis argumentos e insistía en que su amigo los escuchara, él seguía dándole vueltas al asunto. Poco importó que dos mujeres a su lado pareciéramos incómodas con el tema de conversación.

Cito estos episodios en particular (de un repertorio de muchos) porque creo que resumen bien las ideas estereotipadas que se propagan en la cotidianidad y en los medios de comunicación sobre las y los migrantes de nacionalidad colombiana. Entiendo el estereotipo como la imagen o representación de un grupo humano que lo reduce a unas cuantas características fijas e invariables, a menudo negativas. En palabras de Walter Lippmann (2003: 93), quien acuñó este concepto, los estereotipos son imágenes ordenadas y coherentes del mundo, según las cuales los individuos y las cosas "ocupan un lugar inequívoco y su comportamiento responde a lo que esperamos de ellos”.

Otra cosa que tienen en común las anécdotas que relato es que incluyen una respuesta de mi parte, que va desde la broma hasta el intento de argumentación para llenar de contenido esa imagen simplificada y reducida a unos cuantos atributos que no me definen. Mis intentos responden a la pregunta de cómo desmontar esos estereotipos y cómo confrontar las ideas preconcebidas de mis interlocutores. Una noche tomé un taxi y, al escuchar mi acento, el conductor empezó a hablar de cuánto le gustaban la música y las fiestas con mujeres colombianas. Me dijo, "me imagino que usted baila mucho, ¿verdad?”, a lo que yo respondí sonriendo, "pues no, yo no bailo, y casi no escucho salsa. No es mi música favorita”. Mi argumento era que, aunque escuché muchas canciones de salsa a lo largo de mi vida, ser colombiana no me hace, de forma automática, ser una excelente bailarina, ni tampoco hace de la salsa mi género musical preferido. De manera consciente, decidí intentar poner a mi interlocutor en una situación de disonancia, es decir, enfrentarlo a dos referentes de información incompatibles. ${ }^{5}$ Él quedó sorprendido y no daba crédito a lo que yo comentaba. Me preguntaba, “¿en serio?”, y se respondía a sí mismo, "no, no le creo". De acuerdo con Lippmann, no podía concebir que mi comportamiento no correspondiera con sus expectativas. Sentí que, después de esto, se quedó sin tema de conversación. Al intentar romper su referente de la colombianidad se quedó desarmado, desprovisto de otra referencia común a la cual apelar, y lo que vino fue un silencio incómodo entre ambas partes.

La estereotipia es una práctica compleja, que con seguridad todos realizamos cuando nos enfrentamos a lo desconocido. Al usarla tan frecuentemente, dejamos de verlay, por consiguiente, de considerarla como parte de ideologías y prácticas discriminatorias (Cunin, 2006: 6-7). En ocasiones, estas imágenes dejan de ser objeto de chiste y se convierten en promotoras de la discriminación, el acoso y la violencia simbólica, física y sexual. Una conocida, también de nacionalidad colombiana, me contó una vez que alguien la había interrogado sobre si era verdad que las mujeres de ese país "son fáciles". De nuevo en un taxi, en 2011, en un recorrido de no más de diez minutos, un conductor me preguntaba si iba a ver a mis amigos, porque "esas colombianas son tremendas" (risa obscena) y se la pasan de fiesta. Poco importaba que fueran las 11 de la mañana de un día entre semana. Aunque yo reiteraba que era estudiante de posgrado y me dirigía a una reunión con algunos compañeros, mi interlocutor parecía no escuchar; tenía una idea fijada en su mente y, por más esfuerzos que hiciera para revertirla, él insistía, entretenido, riendo y mirándome de reojo o por el espejo retrovisor.

La hipersexualización atribuida a las mujeres colombianas y el cruce de esta idea con otros estereotipos, como el nexo con la droga y la ilegalidad, promueven la estigmatización, excusan la violencia de género, causan impunidad y nos revictimizan cuando una de nosotras sufre una agresión. De esta manera, el estereotipo nos está poniendo en una situación de vulnerabilidad que, por supuesto, genera incomodidad y miedo. La desafortunada muerte de Mile Virginia Martín y la forma en que fue cubierta por los medios de comunicación ilustran lo anterior.

De acuerdo con estos ejemplos, podríamos identificar varios estereotipos que tienen que ver con la corporalidad (sobre todo, pero no solamente, en el caso

5 En torno al concepto de disonancia cognitiva y cómo ésta puede ayudar a romper estereotipos, una contribución novedosa es la de Alexandre Beaudoin Duquette, a quien agradezco su asesoría teórica y sus comentarios sobre el tema. Al respecto, véase su tesis doctoral titulada "Propaganda migratoria canadiense y arte latinoamericano en Montreal: un contrapunteo disonante" (2015). 
de las mujeres), con las actividades económicas que realizamos (el narcotráfico y la delincuencia) y con las formas de sociabilidad (la fiesta). Estoy segura de que las experiencias de vida de otras mujeres y hombres migrantes podrían brindar un panorama aún más completo sobre los repertorios de estereotipos que operan en la vida diaria y, en ese sentido, éste es apenas un ejercicio inicial. Dado que mi condición de mujer es indisociable de las experiencias registradas, puedo decir que los estereotipos antes identificados se cruzan entre sí y con categorías de género. Así, el cuerpo de las mujeres colombianas parece ser percibido como uno voluptuoso, exótico, disponible y exhibible, pero también vinculado con la ilegalidad y lo prohibido.

Una de las veces en que más me he sentido vulnerable y expuesta a la violencia de género estuvo influenciada por mi nacionalidad. En 2011, un taxista que me transportaba dentro de Ciudad Universitaria, en plena tarde, identificó con rapidez mi acento y me preguntó qué hacía en el país, hace cuánto tiempo había llegado y qué carrera estudiaba. Lo que comenzó como una charla casual se convirtió en un monólogo, en el cual el conductor hablaba sobre lo mucho que le gustaban las mujeres colombianas. Me pareció incómodo y contesté con un frío "mm-hmm". Luego vino el piropo, "es que estás bien guapa" -respondido con un silencio de mi parte-, y una declaración espeluznante: "te voy a secuestrar para que te cases conmigo y te quedes aquí en México”. El trayecto no duró más de diez minutos. Recuerdo que continuaba hablándome, pero no pude escucharlo más. La última imagen que tengo es la de un joven en playera que se reía mientras volteaba hacia el asiento de atrás y manejaba a alta velocidad. Mi mano ya estaba en la manija de la puerta del coche $\mathrm{y}$, por suerte, en ese momento me di cuenta de que ya estaba llegando a mi destino.

\section{Fronteras culturales, nacionalidad y estereotipos}

Ernest Gellner (1988: 20) planteaba que lo que entendemos por nación se refiere a una cultura compartida y a un sentimiento de identificación con ella. El problema es que el propio significado del término cultura ha estado sujeto a múltiples discusiones y controversias. Según Pérez Vejo (1999: 56), los nacionalistas han lidiado con el asunto de la definición de lo cultural generando la identificación de una cultura a partir de rasgos particulares que la distingan de los de otras culturas. Así, cualquier elemento que vaya desde la gastronomía hasta la danza puede ser estimado como indicador de dicha identidad nacional
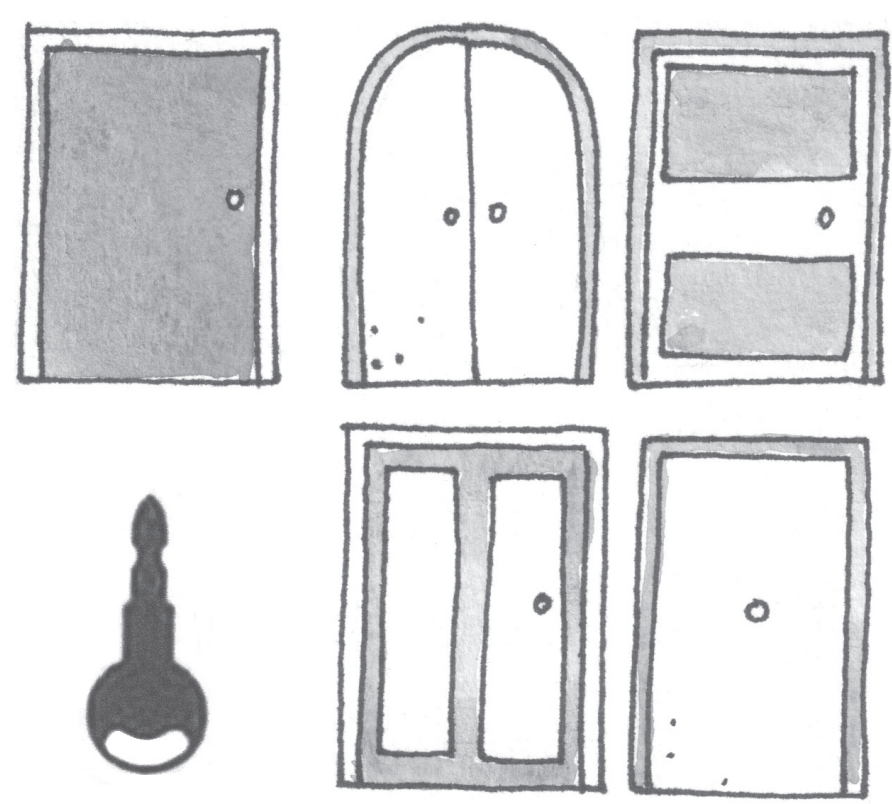

en la medida en que marque diferencias; de igual manera, los rasgos que no coinciden serán considerados ajenos a la propia identidad nacional. Entiendo entonces por identidad nacional la identificación o adscripción a ciertos referentes culturales, históricos, míticos, territoriales, entre otros, que tienen en común las personas que comparten una nacionalidad. No pienso que tales referentes tengan un origen natural, inmemorial o sagrado; por el contrario, creo que son construcciones que, al menos en el caso de los países latinoamericanos, provienen de discursos e historias oficiales o, en otras palabras, de los Estados (y aquí me adscribo al planteamiento de Gellner de que son los Estados los que crean las naciones y no al revés). Retomo estas ideas sobre la nacionalidad porque me permiten destacar un aspecto plenamente aceptado en las ciencias sociales, pero que omitimos al reproducir estereotipos nacionales: el carácter social, histórico y cultural de las naciones contemporáneas y de sus fronteras, tanto geográficas como culturales.

Mi hipótesis es que, en la vida cotidiana, las identidades nacionales que definen "lo mexicano" y "lo colombiano" parecen expresarse por medio de referentes estereotipados que, a su vez, sirven para establecer fronteras culturales entre nosotros y los otros (es decir, quienes comparten una nacionalidad y quienes están excluidos de ella). Estas identidades, expresadas en estereotipos, reafirman fronteras culturales en el día a día de los migrantes y de quienes se relacionan con ellas y ellos, esto es, permiten definir quiénes somos y a qué colectividades pertenecemos en contraposición a los demás. Al hablar de fronteras culturales, aludo a los límites culturales, sociales y simbólicos con base en 
los cuales los individuos se adscriben a o se excluyen de una determinada colectividad social, como puede ser una comunidad nacional.

En su libro clásico sobre las fronteras étnicas, Barth (1976: 1 1-16) planteaba que la continuidad de las unidades étnicas dependía de la conservación de límites entre ellas. Su trabajo advertía acerca de la importancia de enfocarse en los límites étnicos que definían a un grupo, no en el "contenido cultural que encierra”. Aunque Barth aludía a unidades étnicas (concepto que se refería a los sujetos en los cuales la antropología había centrado de manera predominante su interés hasta entonces, pero que no corresponde con las actuales sociedades nacionales), el principio que enunciaba es el mismo que quiero rescatar en este trabajo: que la existencia de la frontera permite establecer la pertenencia a un grupo social determinado, así como la continuidad de dicho grupo. Barth
(1976: 15-16) también confirió un papel central a la autoadscripción en la definición de la etnicidad, con lo cual reconocía que la pertenencia o no pertenencia a una colectividad tiene una dimensión subjetiva, pues no se define por el hecho de compartir ciertos rasgos culturales objetivos y estáticos.

Si bien puede criticarse la poca especificidad de la definición de frontera étnica propuesta por Barth (Giménez, 2006: 136), es justamente la amplitud del concepto lo que hace posible recuperar sus planteamientos al hablar de identidades y estereotipos en un contexto transnacional. De acuerdo con el autor, dado que las identidades así definidas mediante fronteras imponen ciertas restricciones y conductas a los individuos, sus componentes morales y convenciones sociales se vuelven más resistentes al cambio porque se encierran en grupos estereotipados como características de una identidad específica (Barth, 1976: 20). De

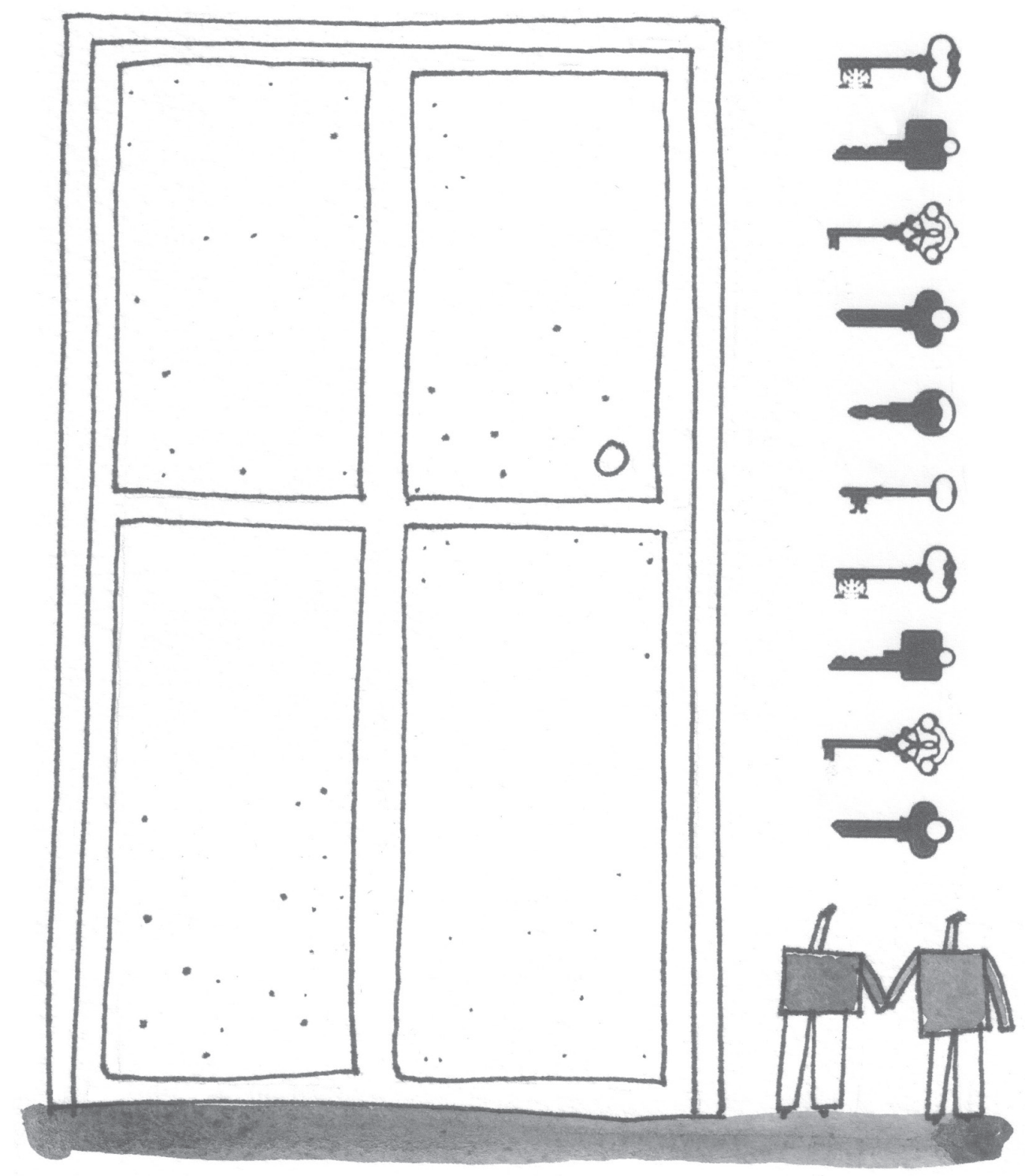


este modo, el encuentro entre diversos grupos (étnicos o nacionales) no disuelve la frontera, sino que, por el contrario, parece reafirmarla, junto con los rasgos culturales expresados en estereotipos que se asumen como distintivos de una colectividad.

Mi argumento es que los estereotipos son un componente central de la frontera cultural existente en la vida cotidiana entre las y los migrantes de nacionalidad colombiana y los miembros de la sociedad receptora. Las fronteras, como las identidades, son relacionales y se construyen, negocian y traspasan en la interacción social. Sin embargo, el problema que plantean los estereotipos nacionales a los cuales me he referido es que tienden a convertir las fronteras culturales en barreras rígidas e infranqueables. El estereotipo, al simplificar lo que creemos saber sobre los otros, nos encierra en espacios determinados y nos designa lugares específicos, dados de antemano, como en el libreto de una gran obra teatral cuyos actores deberíamos jugar papeles que se nos han asignado con anterioridad.

Así, las fronteras culturales y las identidades definidas por ellas parecen alimentarse de la práctica de la estereotipia. Gutiérrez Chong (2004: 42-43) recuerda que la identidad nacional es aprendida y transmitida de forma masiva y se fundamenta en marcadores históricos, culturales y territoriales; con base en ellos se crean arquetipos y estereotipos, los cuales permiten que las personas se identifiquen entre sí por aspectos comunes y se conciban como una comunidad única y defensora de sus patrimonios históricos. El nacionalismo, según la autora, contribuye a la práctica de estereotipar. No creo que la estereotipia sea la única forma de creación, recreación y apropiación de identidades transnacionales, pues éstas se sustentan asimismo en prácticas cotidianas que articulan y reúnen a los migrantes, como las celebraciones, los eventos políticos o los acontecimientos deportivos, entre otros. No obstante, en un mundo en el cual las opiniones tienden cada vez más a concentrarse en el lapso de unos cuantos caracteres circulantes en las redes sociales, me parece coherente que nuestro mapa de la diversidad también se componga de muchas imágenes simplificadas de quienes la conforman.

De tal modo, aunque el estereotipo permite categorizar y reducir al otro a unos cuantos rasgos definidos, ese otro crea a su vez sus propias formas de representarse -lo que Byram y Zarate (1995) llaman autoestereotipo-, a menudo también estereotipadas. El estereotipo, entonces, no sólo sustenta la frontera cultural con unos otros de distintas nacionalidades, sino que además contribuye a que esos otros elaboren un relato identitario que reafirme su peculiaridad y su diferencia con respecto a la sociedad de recepción. Así, durante mi ejercicio de autoetnografía, puse en cuestión ciertos referentes de la colombianidad que llegaban a mí por medio de otros migrantes: que los colombianos bailamos mejor que los mexicanos (conozco muchos paisanos poco dotados para estas artes y me parece que el asunto se reduce a que bailamos diferente), que "nuestras mujeres" son más bonitas (como si las mujeres fuéramos un producto de exportación local), que no compartimos los mismos gustos gastronómicos (porque los gustos locales "no son tan saludables" como los nuestros), o que siempre convivimos mejor entre paisanos. No creo que exista una cultura nacional homogénea, pues nuestros países están construidos sobre la base de una multiplicidad negada en las historias oficiales. Si las nacionalidades y las identidades vinculadas con ellas son construcciones culturales, quizá estamos cayendo en un error al generalizar ciertas cualidades a todo un colectivo nacional. Esta reflexión no niega la existencia de conflictos culturales ni el choque entre diferentes códigos en situaciones de migración y extranjería. Empero, busca advertir sobre la facilidad de resolver esos malentendidos con la fórmula "es que las / los colombianos / mexicanos son/somos de tal manera".

Otra de mis hipótesis es que hay ciertas correspondencias entre los estereotipos asignados a las y los migrantes de nacionalidad colombiana y los autoestereotipos y autopercepciones de dichos migrantes. Empero, en este último caso, los referentes en común son dotados de nuevos sentidos, asignándoles características positivas y dignas de destacar. Por obvias razones, esta tarea no resulta coherente con el estereotipo del narcotráfico y la delincuencia, pero sí es posible con los de la corporalidad y la sociabilidad de los cuales he hablado antes. En otras palabras, en nuestras formas de percibirnos hay elementos del estereotipo que se nos asigna, los cuales son resignificados en la vida cotidiana como cualidades y ventajas de nuestra nacionalidad. Un tema que queda por analizar es hasta qué punto estos autoestereotipos se relacionan con nuestra propia historia de creación de una identidad nacional.

\section{A manera de conclusión}

Pocos días después de las elecciones en Estados Unidos, un taxista, en medio del tráfico de la hora pico, me expresaba, con tono de desaprobación, que "ya no cabemos todos aquí. Y peor, ahora que el imbécil del Donald [Trump] va a devolver a un montón de gente. Todavía Peña Nieto dice que bienvenidos, que ésta 
es su casa... Somos muchos, vienen de todos lados, vienen muchos colombianos..." Éste es, en realidad, un argumento económico, que sitúa a los inmigrantes como competidores potenciales $\mathrm{y}$, por tanto, como invasores que quitan oportunidades a los lugareños, ${ }^{6}$ idea que no dista mucho del discurso de Trump sobre los migrantes que cruzan la frontera hacia Estados Unidos. Si los inmigrantes residentes representan menos de $1 \%$ de la población mexicana, ¿es real esta amenaza? Una encuesta realizada en 33 países y presentada el año pasado por el diario británico The Guardian mostraba que los mexicanos piensan que cerca de $22 \%$ de su población ha nacido en el extranjero, lo cual sugiere que hay una sobrevaloración del peso de los migrantes en la vida nacional. ${ }^{7}$ Además, es paradójico que, mientras que en México los inmigrantes son percibidos como invasores, éste sea uno de los países que más emigrantes internacionales registra en el mundo (segundo lugar después de la India, con más de 13 millones de personas) (Caicedo y Morales Mena, 2015: 45).

En una asamblea de barrio, una vecina, preocupada por la "creciente" inseguridad en nuestra colonia, decía que las casas debían estar protegidas con sistemas de seguridad porque en los edificios de departamentos vivían muchos centroamericanos. De nuevo, los paralelos con los discursos del electo presidente de Estados Unidos son impresionantes:

Los Estados Unidos se han convertido en un tiradero de los problemas de los demás [...]. Cuando México envía su gente, no están enviando lo mejor. No te están enviando a ti ni a ti. Están enviando gente que tiene montones de problemas, y ellos están trayéndonos esos problemas. Están trayendo drogas. Están trayendo crimen. Son violadores. Y algunos, asumo, son buenas personas [The Washington Post, 2015: s. p.; traducción propia].

De regreso a México, varias veces, en situaciones de conflicto, noté que las demás personas solían recordarme mi extranjería como impedimento para protestar sobre algo. Aunque en una ocasión intenté resolver por la vía legal los problemas vecinales, la respuesta que recibí de parte de mi casero fue "en México no es como en Colombia”. Esta idea de que "en tu país es diferente" impide que los extranjeros reclamemos ciertos derechos o nos quejemos ante circunstancias que consideramos injustas o incluso ilegales, y nos disuaden de utilizar los canales institucionales necesarios para ello. Impedir el reclamo de un derecho con base en la extranjería del interlocutor es una forma de remarcar una frontera cultural rígida, que remite a una experiencia de liminalidad, como definió Victor Turner a los estados de ambigüedad que distinguen la fase de separación durante los ritos de paso. El rito de la migración parece no concluir jamás, pues los “entes liminales" extranjeros no pueden alcanzar una fase de "reincorporación" que consume su paso a un estado relativamente estable, en el cual adquieran derechos y obligaciones coherentes con su posición social (Turner, 1988: 101 - 102). Si bien en este trabajo documento algunos estereotipos asociados con las y los migrantes de nacionalidad colombiana, es necesario continuar explorando de qué manera tales estereotipos, junto con las prácticas sociales que conllevan, se insertan en actitudes más generales hacia los extranjeros.

A lo largo de este artículo, he entendido la frontera como un espacio en el que se marcan diferencias simbólicas y en el que se define quiénes somos nosotros y los otros. Marc Augé (2007: 21) apuntaba que "una frontera no es una barrera, sino un paso, ya que señala, al mismo tiempo, la presencia del otro y la posibilidad de reunirse con él". Las fronteras, para Augé, indican "la necesidad de aprender para comprender". La vivencia de las fronteras culturales abre entonces una posibilidad de aprendizaje sobre la diferencia, de cuestionamiento de nuestras propias preconcepciones, de apertura y de complejización de las visiones estereotipadas con las que operamos en la vida cotidiana. Benedict Anderson (1991) hablaba del nexo entre la religión y la nación moderna, y Pérez Vejo (1999: 33-34) mencionaba que el nacionalismo asume las características de una nueva religión, sustituyendo de manera progresiva a las antiguas religiones como núcleos de la identidad colectiva. Ese carácter sagrado de la nación y de los relatos que la sustentan genera una identificación emocional que no se rompe con facilidad y que dificulta la autocrítica y la crítica externa porque, en cuestiones de la nacionalidad, como de la religión, es usual llegar a sentirse poseedor de la verdad sobre los otros. Por eso propongo pensar la nacionalidad como un accidente, como una contingencia y como algo que no necesariamente nos define en cuanto sujetos.

6 Esta percepción de los migrantes ha sido documentada también por Byram y Zarate (1995: 8).

7 Véanse "Revealed: The Gap between What you Know about your Country and the Reality" <https://www.theguardian. $\mathrm{com} / \mathrm{society} /$ datablog/2015/dec/02/revealed-gap-between-your-knowledge-reality> [5 de octubre de 2016] y "How Well do you Really Know your Country? Take our Quiz" <https://www.theguardian.com/world/ng-interactive/2015/dec/02/ how-well-do-you-really-know-your-country-take-our-quiz> [5 de octubre de 2016]. 


\section{Fuentes}

Anderson, Benedict

1991 Comunidades imaginadas. Reflexiones sobre el origen y la difusión del nacionalismo, Fondo de Cultura Económica, México, 315 pp.

Animal político

2016 "La modelo colombiana Stephanie Magón tomó impulso y se lanzó de la azotea: Procuraduría", en Animal Político, 4 de agosto <http: / / www. animalpolitico.com/2016/08/la-modelocolombiana-tomo-impulso-se-lanzo-la-azotea$\mathrm{pgj} />$ [5 de octubre de 2016].

Atkinson, Paul

1997 “Narrative Turn or Blind Alley?", en Qualitative Health Research, vol. 7, núm. 3, pp. 325-344.

Augé, Marc

2007 Por una antropología de la movilidad, Gedisa, Barcelona, 93 pp.

BARTH, FREDRIK (COMP.)

1976 Los grupos étnicos y sus fronteras. La organización social de las diferencias culturales, Fondo de Cultura Económica, México, 204 pp.

Beaudoin Duguette, Alexandre

2015 "Propaganda migratoria canadiense y arte latinoamericano en Montreal: un contrapunteo disonante", tesis doctoral, Universidad Nacio-

BYRAM, Michael nal Autónoma de México, México.

Y GENEVIÈve ZaRATE

1995 Young People Facing Difference. Some Proposals for Teachers, Council of Europe, Estrasburgo, $59 \mathrm{pp}$.

Caicedo, Maritza

y Agustín Morales Mena

2015 Imaginarios de la migración internacional en México. Una mirada a los que se van y a los que llegan, Universidad Nacional Autónoma de México, México, $216 \mathrm{pp}$.

Cárdenas, Mauricio y Carolina Mejía

2006 Migraciones internacionales en Colombia: ¿qué sabemos? (Documentos de Trabajo, 30), Centro de Investigación Económica y Social, Bogotá <http: / / www.repository.fedesarrollo.org.co/ handle/ $11445 / 810>$ [ $1^{\circ}$ de abril de 2016].

Chang, Heewon

2008 Autoethnography as Method, Left Coast Press, Walnut Creek, 229 pp.

Chang, Heewon

2013 "Individual and Collaborative Autoethnography as Method. A Social Scientist's Perspective”, en Stacy Holman Jones, Tony Adams y Carolyn Ellis (eds.), Handbook of Autoethnography, Left Coast Press, Walnut Creek, pp. 107-122.

Clifford, JAmes

1995 Dilemas de la cultura. Antropología, literatura $y$ arte en la perspectiva posmoderna, Gedisa, Barcelona, 432 pp.

Coffey, Amanda

1999 The Ethnographic Self: Fieldwork and the Representation of Identity, Sage, Londres, $192 \mathrm{pp}$.
COPRED

2015 Informe anual, 2015, Consejo para Prevenir y Eliminar la Discriminación de la Ciudad de México, México <http: / / copred.cdmx.gob.mx/ wp-content / uploads / 2016 / 05 / INFORMEANUAL-2015-COPRED-FINAL.pdf> [5 de octubre de 2016].

Cunin, Elisabeth

2006 "El Caribe visto desde el interior del país: estereotipos raciales y sexuales", en Revista de Estudios Colombianos, núm. 30, pp. 6-14.

Gellner, ERnest

1988 Naciones y nacionalismo, Alianza Editorial, Madrid, $189 \mathrm{pp}$.

Giménez, Gilberto

2006 "El debate contemporáneo en torno al concepto de etnicidad", en Cultura y Representaciones Sociales, año 1, núm. 1, pp. 129-144.

Gutiérrez Chong, Natividad

2004 Mujeres y nacionalismos en América Latina: de la Independencia a la nación del nuevo milenio, Instituto de Investigaciones Sociales-Universidad Nacional Autónoma de México, México, $368 \mathrm{pp}$.

LIPPMANN, WALTER

2003 La opinión pública, Langre, Madrid, 333 pp. [1922].

Neira OrJuela, Fernando

2010 "Los inmigrantes colombianos en México. Una caracterización sociodemográfica”, en Ernesto Rodríguez Chávez (coord.), Extranjeros en México, continuidades y aproximaciones, Instituto Nacional de Migración, México, pp. 395-417.

Pérez Vejo, Tomás

1999 Nación, identidad nacional y otros mitos nacionalistas, Ediciones Nobel, Oviedo, 203 pp.

Ribeiro, Gustavo Lins

1989 "Descotidianizar. Extrañamiento y conciencia práctica, un ensayo sobre la perspectiva antropológica", en Cuadernos de Antropología Social, vol. 2, núm. 1, pp. 65-69.

Rodríguez Chávez, ERnesto

y Salvador Cobo

2012 Extranjeros residentes en México, una aproximación cuantitativa con base en los registros administrativos del INM, Instituto Nacional de Migración, México, 78 pp.

The Washington Post

2015 "Full Text: Donald Trump Announces a Presidential Bid", en The Washington Post, 16 de junio <https://www.washingtonpost.com/ news / post-politics /wp / 2015/06/16/fulltext-donald-trump-announces-a-presidentialbid/> [5 de octubre de 2016].

TURNER, VICTOR

1988 El proceso ritual. Estructura y antiestructura Taurus, Madrid, $217 \mathrm{pp}$.

WALFORD, GEOFFREY

2004 "Finding the Limits: Autoethnography and Being an Oxford University Proctor", en Qualitative Research, vol. 4, núm. 3, pp. 403-417. 